\title{
LAS REFORMAS DE LA EDUCACIÓN SUPERIOR Y LOS PROBLEMAS DEL DESARROLLO EN AMÉRICA LATINA
}

\author{
Rodrigo AROCENA*
}

\begin{abstract}
RESUMEN: Se vincula la evolución de la educación superior en América Latina con los cambiantes estilos y estrategias para el desarrollo. Se discuten las tendencias recientes en las reformas educativas y se las ejemplifica mediante referencias a ciertos casos nacionales. Se sostiene que la "idea latinoamericana de universidad" sugiere una agenda para la transformación de la educación superior que puede favorecer las posibilidades de un nuevo desarrollo.
\end{abstract}

Palabras claves: Educación superior. Desarrollo. América Latina.

\section{HigHER EDUCATION REFORMS AND DEVELOPMENT PROBLEMS IN LATIN AMERICA}

ABSTRACT: This paper connects the evolution of Higher Education in Latin America to changing development styles and strategies. It discusses the recent trends in educational reforms and exemplifies them through references to national cases. It asserts that the "Latin American idea of University" suggests an agenda to transform Higher Education that may enhance the possibilities of a New Development.

Key words: Higher education. Development. Latin America.

* Unidad de Ciencia y Desarrollo, Facultad de Ciencias, Universidad de la República (Uruguay). E-mail: roar@fcien.edu.uy 
Las reformas de la educación superior y los problemas del desarrollo en...

\section{Introducción: miradas alternativas}

¿Desde dónde mirar la cambiante, heterogénea y contradictoria realidad de la educación superior (ES) en América Latina?

Cada punto de vista resalta ciertas cuestiones y oculta otras o las relega a posiciones periféricas. Un enfoque consistente genera una agen$d a$. Lo que sucede no es por supuesto una consecuencia lineal de lo que figura en la agenda predominante; usualmente, cambios y permanencias son, más que el fruto de proyectos deliberados, las resultantes a menudo inesperadas y hasta indeseadas de las interacciones conflictivas entre intereses múltiples, dotados de variables cuotas de poder. Pero la agenda prevaleciente - en tanto conjunto de asuntos priorizados, en torno a los cuales se procesan los debates y se adoptan decisiones - incide poderosamente en la delimitación de alianzas y enfrentamientos, en lo que efectivamente acontece y en su interpretación.

Durante el último cuarto de siglo, la agenda predominante en la ES latinoamericana ha estado moldeada por la mirada desde afuera. La mayoría de los gobiernos, sectores empresariales, medios comunicacionales afines y organismos internacionales de crédito convergieron en una visión muy crítica de las universidades públicas de la región. Las consideraron poco funcionales para el nuevo tipo de inserción económica, que reputaban imprescindible, de América Latina en el mundo. Semejante consideración inspiró el tipo de reformas de la ES que con mayor fuerza fueron impulsadas.

Los intentos transformadores desde afuera, característicos de los años ' 80 y ' 90 , indujeron modificaciones muy significativas. Pero no dieron lugar a una transformación integral de la Es latinoamericana. Tres factores entrelazados contribuyen a explicar que así sucediera. En primer lugar, si bien América Latina experimentó durante el período un gran cambio - caracterizado como el tránsito de una matriz "estadocéntrica" de relaciones sociales a otra de tipo "mercadocéntrica" -, sus pobres consecuencias económicas, políticas e ideológicas no ofrecieron demasiado respaldo a las propuestas educativas asociadas. En segundo lugar, éstas últimas, aunque pusieron de relieve problemas sustantivos e incluso ofrecieron elementos útiles para su solución, eran básicamente equivocadas y contraproducentes. En tercer lugar, se toparon con fuertes resistencias. 
Tales resistencias tuvieron como inspiración orientadora la mirada desde la tradición. $\mathrm{O}$, mejor dicho, desde el entrelazamiento de varias tradiciones: la que ha mantenido vigencia desde el surgimiento de las universidades como corporaciones autónomas; la tradición latinoamericana de la Reforma de Córdoba; la tradición también autonómica asociada a la noción de "República de la Ciencia". Diversos y a menudo conflictivos intereses materiales han sostenido semejantes ideales. Sus principales defensores han sido, claro está, actores constituidos dentro de las instituciones de Es. Pero esos actores internos han sabido encontrar apoyos para sus reivindicaciones en importantes movimientos y sectores externos.

Así, a las reformas desde afuera se opusieron, sin lograr derrotarlas pero frecuentemente limitándolas en mayor o menor grado, las resistencias desde adentro. Estas, aunque no carecieron de ciertas formulaciones generales compartidas, no llegaron a levantar proyectos reformadores alternativos, e incluso tuvieron grandes dificultades para presentar su propia agenda ante la opinión ciudadana.

El fracaso de las políticas neoliberales, y el relativo retroceso de las ideologías que las inspiran, abre nuevas posibilidades para América Latina. Otras dinámicas y proyectos afloran, a la vez impulsados y constreñidos por las difíciles condiciones socioeconómicas prevalecientes. Para los sectores progresistas en sentido amplio, se plantea hoy en mejores condiciones que ayer la lucha democrática por la definición ciudadana de la agenda prioritaria. En ésta podrían encontrar un lugar propuestas educativas genuinamente renovadoras.

A través de la elaboración en las páginas siguientes de las esquemáticas afirmaciones precedentes, este texto sostiene que uno de los puntos de vista que pueden contribuir a clarificar la problemática de la ES es la mirada desde el futuro del (sub) desarrollo.

Adoptamos ese punto de vista porque sospechamos que en América Latina se ha abierto una pequeña y probablemente transitoria "ventana de oportunidad" para un nuevo desarrollo - en tanto mejora sustentable de la calidad de vida y expansión de las libertades -, cuyo aprovechamiento dependerá en medida significativa de lo que acontezca en el terreno de la Es. A la inversa, el futuro de ésta última se verá grandemente influido por lo que acontezca en el terreno del desarrollo. 
Las reformas de la educación superior y los problemas del desarrollo en...

\section{Reforma universitaria y desarrollo en el acontecer latinoamericano}

En la historia de América Latina, ha sido muy significativa la interacción de las reformas de la ES con las políticas para el desarrollo. Esa interacción suministra el hilo conductor de lo que sigue.

La única transformación de la Es latinoamericana con envergadura de "revolución académica" ha sido el Movimiento de la Reforma Universitaria que tuvo su Marsellesa en el Manifiesto de los estudiantes de Córdoba de 1918. Fue una de las expresiones más vigorosas y probablemente la más original del cuestionamiento al orden oligárquico que rigiera en el continente desde la independencia. Cobró fuerza cuando se agotaba el tipo de inserción externa neocolonial que era la contracara de la dominación oligárquica. Al tiempo que se debilitaba el "crecimiento hacia afuera" primario-exportador, avanzaban entretejidas la industrialización y la democratización, y con ellas la reforma universitaria. No fue por cierto un avance sin sobresaltos ni retrocesos. En su curso se fue conformando una "idea de universidad" orientada hacia su propia democratización como clave para colaborar con la democratización de la sociedad en su conjunto. En ese marco adquieren todo su sentido las reivindicaciones definitorias de la Reforma de Córdoba: el cogobierno, la autonomía, la relevancia de la extensión universitaria, el acceso irrestricto a la ES, la libertad de cátedra, el cuestionamiento a la inamovilidad de los docentes, el relacionamiento con los sectores sociales postergados. Esa "idea de universidad" estaba llamada a tener amplio arraigo y a vincularse con la noción de desarrollo autónomo como transformación social integral. Esta emergió vigorosamente, a partir de los años ' 50 , en la escena política e ideológica del continente, elaborada principalmente desde la CEPAL primero, y después también desde la teoría de la dependencia. La "revolución académica" desencadenada en Córdoba y la concepción latinoamericana clásica del desarrollo llegaron tanto a vivir como a languidecer juntas (Arocena y Sutz, 2001a; 2004).

La gran crisis de comienzos de los ' 80 alimentó lo que sus propios portaestandartes caracterizaron como una "contrarrevolución" en el pensamiento sobre el desarrollo (ver Toye, 1987). Esta encontró un camino bastante despejado, pues aquella concepción latinoamericana había conocido ya tropiezos grandes; las estrategias que inspiró no generaron éxitos mayores y duraderos; sus enfoques no colaboraron a cap- 
tar la gravitación de grandes fenómenos como el nuevo papel social y económico del conocimiento. Para comprender esto último, tampoco resultaba demasiado fecunda la ideología de la Reforma de Córdoba. La misma había ya transformado profundamente la ES de varios países latinoamericanos y, aunque incidió bastante menos en algunos otros, no había dejado de influenciar a ninguno. Sus postulados reverdecieron, con el proceso más auspicioso de los '80 y tempranos '90 en América Latina, el avance vigoroso de la democratización política. En las plataformas antidictatoriales, encontraron un lugar la autonomía universitaria, el cogobierno e incluso la eliminación de las restricciones al ingreso o la unidad de las tareas de enseñanza, investigación y extensión. Pero, a partir de entonces, el ideario de Córdoba, confrontado con mundos universitarios mucho más grandes y complejos que aquél en el que surgiera, no fue capaz de impulsar transformaciones de la ES a la altura de los nuevos problemas. En ese contexto, intereses e ideas similares a los que plasmaron una "contrarrevolución" en el desarrollo impulsaron una "contrarreforma" en la Es.

\section{Las reformas desde afuera y sus avatares nacionales}

Comenzando en los '80, propuestas similares para la ES fueron impulsadas por la mayor parte de los gobiernos latinoamericanos, si bien la energía con que lo hicieron y los éxitos que obtuvieron fueron bastante diferentes. Se apuntó a modificar las formas de financiamiento y a implantar sistemas de evaluación, al tiempo que se preconizaba un relacionamiento más estrecho con el sector productivo. La agenda prioritaria, los principales cambios impulsados y las herramientas de política empleadas coincidieron en grado sumo con las recomendaciones del Banco Mundial. El proceso se inscribió en la lógica general de la reforma del Estado preconizada por las corrientes a la sazón dominantes en el pensamiento sobre el desarrollo. Las reformas en cuestión favorecieron la mercantilización del trabajo académico y, más en general, la privatización del conocimiento (Bentancur, 2002, p. 7; Dourado, Catani y Oliveira, 2003, p. 20; García Guadilla, 2003, p. 19).

Además, ese proceso de cambios motorizado desde afuera de las instituciones de ES tendió, en general, a disminuir su autonomía así como los niveles de participación efectiva de los órdenes universitarios - particularmente del estudiantado - en la orientación del siste- 
Las reformas de la educación superior y los problemas del desarrollo en...

ma educativo. Explícita o implícitamente, se buscó debilitar los vínculos establecidos, durante el auge de la reforma universitaria y de la búsqueda de caminos para el desarrollo autónomo, entre las universidades públicas latinoamericanas y los movimientos sociales y políticos contestatarios.

Se configuró así, de hecho, un proyecto de "contrarreforma" cuyos distintos rasgos y resultados ejemplificaremos mediante sumarias referencias a ciertos casos nacionales. Concentramos nuestra atención en algunos países hispanoamericanos. Brasil, por su entidad y especificidad, requiere un tratamiento más pausado; al respecto, ver por ejemplo Catani y Oliveira (2002), Catani y Portela de Oliveira (2000), Dias Sobrinho (2002), Sguissardi (2000) y otros textos incluidos en este mismo volumen.

Chile, donde el impacto de la Reforma de Córdoba resultara comparativamente menor, constituyó - dictadura militar mediante el caso más temprano y neto de aplicación de la doctrina neoliberal, en la sociedad en general y también en la ES, donde se la impulsó con vigor a partir de 1981. El aporte financiero estatal a las universidades llegó a cubrir no más del $50 \%$ de su presupuesto, lo que obligó a las universidades tradicionales a incrementar sus aranceles de manera muy gravosa para las familias de recursos escasos o medios. Los conflictos generados por este panorama devinieron endémicos. Las universidades fueron inducidas a comportarse como empresas en el mercado, definiendo qué cursos dictar o no en función de la relación costo-beneficio, cerrando programas que no resultaron rentables, exigiendo financiamiento externo para realizar tareas de extensión (Campbell, 2000, p. 119; González, 2003, p. 148). Los gobiernos democráticos promovieron un papel estatal mayor en la regulación de la ES y procuraron modificar el modelo heredado de la dictadura, pero no tuvieron suficiente respaldo parlamentario para ello. La incidencia del carácter privado ha llegado a ser la característica dominante del sistema; buena parte de las instituciones privadas tienen bajo nivel, si bien algunas presentan un desempeño académico mejor, incluso a nivel de postgrado, pero no hay "universidades de investigación" privadas (Bernasconi, 2003). Sin desmedro de ajustes de entidad, orientados a garantizar más equidad y calidad, el modelo establecido en 1981 sigue vigente en lo sustancial (IESALC, 2003). 
Chile ha constituido el paradigma de referencia para numerosos organismos y grupos; el Banco Mundial procuró convencer de que lo adoptaran como tal a casi todos los gobiernos latinoamericanos, y en muchos casos lo logró. Pero, en contextos distintos, los resultados también lo fueron.

En la estructura extremadamente diferenciada de la ES en Colombia tampoco fue históricamente muy grande la influencia de la Reforma de Córdoba. Allí también se promovió una transformación sustancial (Orozco Silva, 1998; IESALC, 2003) pero, a diferencia del caso chileno, ello tuvo lugar recién en la década del ' 90 y no bajo un régimen dictatorial, sino en el marco de la Reforma Constitucional de 1991, que consagró la autonomía universitaria y la participación de la comunidad educativa en la dirección de los institutos de Es. La ley de 1992 apuntó a precisar ese marco constitucional y a impulsar la investigación científica y tecnológica en las universidades. Se sostiene que su principal consecuencia fue la creación de un sistema nacional de acreditación y la promoción de una cultura de la evaluación. Se ha discutido mucho en tiempos recientes acerca de la reforma de dicha ley, lo que ejemplifica la búsqueda de nuevos rumbos como actitud que se ha venido extendiendo en la Es latinoamericana durante los años recientes.

Una transformación legal más reciente tuvo lugar en Ecuador, donde la ley de 2000 estableció un Consejo Nacional de Educación Superior, con un delegado del sector productivo. Además se puso en funcionamiento el Consejo Nacional de Acreditación. Entre 1998 y 2002, el Congreso creó 10 nuevas universidades (IESALC, 2003). En un contexto signado por grandes conflictos sociales y políticos, ese país ilustra pues tres rasgos generales de la evolución reciente de la ES: la expansión cuantitativa, el intento de vincularla con la producción y el énfasis en la acreditación.

Ya recordamos que la reforma universitaria latinoamericana fue una expresión mayor del enfrentamiento a los regímenes oligárquicos. Estos resistieron con mayor éxito en Colombia que en Venezuela, donde la reforma se abrió rápido camino a la caída de la dictadura en 1958. Esa dinámica política e ideológica, junto con los abundantes recursos provenientes del petróleo, posibilitó la extensión de la ES a todas las ciudades importantes y el incremento de la matrícula de 11 mil estudiantes, en 1957, a 1 millón, en 2001. En tal contexto, durante los 
Las reformas de la educación superior y los problemas del desarrollo en...

'90, la "contrarreforma" no encontró mayor asidero, pero tampoco la ideología de la reforma ofrecía ya elementos para adaptar la ES venezolana a los nuevos tiempos. No pocos cambios se efectuaron, en materia por ejemplo de reconocimiento del trabajo académico, creación de empresas universitarias y parques tecnológicos en las universidades y apoyo a estudiantes de escasos recursos; pero la mayoría de las innovaciones ha tenido un carácter más bien puntual (García Guadilla, 1998; Parra Sandoval, 2002; IESALC, 2003). La polarización social y política que vive el país incide considerablemente en la ES y en la incertidumbre acerca de sus perspectivas (Parra Sandoval, 2002, y Albornoz, 2003, dibujan perspectivas bien diferentes).

También en Uruguay la ideología de Córdoba se entretejió con el avance de la democratización; cuando concluyó en 1985 la dictadura, fueron restaurados el cogobierno, la autonomía universitaria y el ingreso irrestricto a la ES. La primera universidad privada fue autorizada en 1984, en los momentos finales del régimen militar. La ES privada fue reglamentada en 1995; la matrícula del sector es al presente alrededor del $10 \%$ del total. Existe una única universidad pública, que da cuenta no sólo del grueso de la enseñanza de ese nivel sino asimismo de la mayor parte de la investigación que se realiza en el país; en ella se han registrado varias innovaciones significativas aunque más bien aisladas, que no se inscriben en una transformación global. En Uruguay no llegó a concretarse un acuerdo con el Banco Mundial; las reformas "desde afuera" típicas de los '90 fueron impulsadas con mucha debilidad. Este es un caso de claro bloqueo de la "contrarreforma”, en el que por otra parte la ES cambió en conjunto poco, de manera predominantemente inercial.

En Argentina fue donde con más claridad se enfrentaron durante los '80 y '90 la tradición de Córdoba y la “contrarreforma”. El gobierno (1983-1989) que actuó inmediatamente después de la última dictadura militar promovió la reimplantación del modelo de la reforma universitaria, junto a una concepción más moderna de la investigación. Como en Uruguay, se restauró el cogobierno y se suprimieron tanto los exámenes de ingreso como el numerus clausus. Ese gobierno rechazó el diagnóstico y las propuestas provenientes del Banco Mundial, que a continuación el régimen de Menem (1989-1999) hizo suyas, plasmándolas en la Ley de Educación Superior de 1995, la cual limitó la autonomía y abrió posibilidades de restringir el acceso así 
como de establecer aranceles, contradiciendo lo establecido en la Constitución del año anterior (Vior, 2000). Dicha ley sobrecargó de espacios de gobierno al sistema de ES y formalizó el papel central de la correspondiente Secretaría del Poder Ejecutivo (Krotsch, 1998). En Argentina hacia el 2000 el proyecto de "contrarreforma" se expresaba, en los papeles, con nitidez difícil de igualar. Se proponía incluso privatizar la gestión de las universidades concursando la concesión de las mismas, con lo que desaparecerían la autonomía, el cogobierno y la designación de docentes por concurso (Coraggio, 2003, p. 111). Esa postura ideológica impulsa a las universidades "hacia la construcción de una nueva identidad que las asemeja al 'supermercado', donde el estudiante es cliente, los saberes una mercancía y el profesor un asalariado enseñante" (Molis, 2003, p. 204). Tras el derrumbe económico de fines del 2001, el país entró en una nueva etapa política e ideológica, donde las cuestiones de la educación y del desarrollo se abren a una discusión mucho más amplia.

En suma, durante la década en curso la "contrarreforma" ha perdido parte de su gravitación previa; son varios los países donde ya no define casi en solitario la agenda. Pero mantiene su hegemonía en otros casos, mientras que la búsqueda de alternativas, si bien ha cobrado cierto vigor, tiene en todo caso carácter muy incipiente.

Más en general, entre la situación de hoy y la de la década anterior se aprecia una continuidad en las políticas efectivamente ensayadas, en el hecho de que el principal impulso al cambio viene "desde afuera" y, sobre todo, en la persistencia de la crisis de la ES. Esa continuidad ha sido especialmente destacada en el caso de México pero, en mayor o menor grado, también se constata en gran parte de América Latina.

En un balance de los últimos 20 años, seguramente lo más grave es la medida en que se entretejen las severas carencias de la ES en materia de calidad y de recursos con las recurrentes crisis socioeconómicas del continente. Un ejemplo extremo de ello es Paraguay, país en el que tales carencias son endémicas pese a que la cobertura del sector sólo alcanza al 7\% del correspondiente grupo de edad, y donde la crisis nacional apunta al empeoramiento general de la situación. Pero también Paraguay es un ejemplo, entre varios otros, de un fenómeno que en el balance aparece entre los más auspiciosos: la vinculación entre los procesos de democratización y las apuestas colectivas a la educación como 
Las reformas de la educación superior y los problemas del desarrollo en...

clave de progreso colectivo. Esa vinculación de larga data en la historia latinoamericana volvió a sentirse en Paraguay cuando, en 1989, el final de una larga pesadilla dictatorial indujo una apuesta a la transformación educativa para la consolidación de la democracia.

\section{Cuadro de situación}

La bibliografía consultada, varios aspectos ya mencionados y algunos analizados más detenidamente en otro texto (Arocena, 2003) esbozan un panorama de la Es latinoamericana al comenzar el nuevo siglo que, muy apretadamente, puede resumirse como sigue.

La ES sigue diferenciándose y aún fragmentándose cualitativamente. Al mismo tiempo, sigue creciendo rápidamente el número de estudiantes, de instituciones e incluso de docentes; aún así, la proporción de jóvenes que acceden a este nivel educativo es mucho menor que en los países "centrales". Un rasgo notable, constatado también en varias otras regiones, es la rápida feminización de la matrícula terciaria.

También ha seguido creciendo en términos absolutos y aún relativos el componente privado de la Es latinoamericana. Se sostiene que en América Latina se está conformando un "modelo tripartito": público, privado local y privado internacional (IESALC, 2003); la gravitación de la tercera parte de ese modelo es uno de los muchos aspectos ligados a la expansión de la educación virtual. La proliferación de "alianzas estratégicas" entre instituciones privadas de la región y de fuera de ella sugiere que, más que a la conformación de un modelo tripartito, asistimos a la creciente internacionalización del componente privado de la Es latinoamericana.

El accionar estatal se ha caracterizado por un énfasis en la evaluación, que se va desplazando a la acreditación. Los procedimientos vinculados han recortado la autonomía de las instituciones de ES; han estado a cargo principalmente de organismos dependientes del Poder Ejecutivo, donde predominan los criterios gerenciales característicos de las reformas impulsadas en los '90 (Bentancur, 2002, p. 96). Esos criterios se vinculan con una manera de entender la "rendición de cuentas" (accountability) que favorece una tendencia de alcance mundial, el creciente control de la gestión universitaria por administradores profesionales (Altbach y Davis, 2000, p. 29). Todo ello no estimula la par- 
ticipación democrática, pero la centralización de las decisiones tampoco está mostrando demasiada capacidad para implantar reformas amplias y consistentes, en buena medida porque se la ha utilizado para extender la asignación de recursos mediante fondos concursables a un extremo tal que la evolución institucional depende más del arbitrio de los "semi-mercados" así creados que de las decisiones explícitas de los organismos de conducción.

Los gobiernos han insistido en que las universidades públicas deben vincularse estrechamente con el sector productivo. La cuestión ha dado lugar a grandes polémicas y respuestas diferenciadas pero, como tendencia general, cabe sostener que esas universidades han llegado a realizar importantes esfuerzos en esa dirección sin encontrar demasiado eco, ni en el empresariado ni en los propios gobiernos. La colaboración de las universidades con la producción, si bien muestra incontables ejemplos, no ha adquirido verdadera entidad, principalmente porque el conocimiento avanzado juega un papel escaso en la economía latinoamericana y porque persiste la antigua tendencia a comprar afuera el conocimiento que se reputa necesario. Ambos rasgos marcan el desempeño estatal, a veces con mayor fuerza que el privado. En esta materia persiste pues "la soledad del actor universitario" (Arocena y Sutz, 2001b). Esta se ha visto agravada por "el creciente desempleo y la emigración de profesionales y técnicos” (IESALC, 2003), frente a los cuales las respuestas gubernamentales han sido promedialmente pobres.

Lo anotado se suma a otros elementos para sugerir que persiste asimismo la relativa subestimación gubernamental de la ES en América Latina. Ello responde en grado considerable a la primacía de políticas para el desarrollo que, más allá de los dichos, no captan la relevancia contemporánea de la alta calificación, la generación endógena de conocimientos y la innovación técnico-productiva.

En el contexto que venimos esbozando no puede sorprender que los problemas de financiamiento y de "masificación" sigan ocupando el centro de la atención e incluso se agraven, como consecuencia del "sexenio perdido" del que la región recién parece emerger (CEPAL, 2003). Así por ejemplo, con respecto a Centroamérica se destaca una "dramática reducción de la relación entre presupuesto de la ES y PIB” (IESALC, 2003).

Tales problemas son sin duda muy difíciles de resolver. En las universidades públicas de acceso irrestricto, han contribuido a alargar 
Las reformas de la educación superior y los problemas del desarrollo en...

considerablemente la duración promedial de los estudios y a generar impactantes niveles de deserción en el primer año. Cuando las universidades públicas de alto nivel tienen cupos restringidos, los que acceden son sobre todo los hijos de las familias pudientes, mientras que los demás por lo general tienen que buscar un lugar en instituciones de menor calidad, a menudo costosas. La antigua formación de élite tiende a desplazarse a algunos programas de postgrado.

El desarrollo del cuarto nivel de enseñanza ha sido un aporte fundamentalmente de las universidades públicas, que dan cuenta del 75\% de la correspondiente matrícula (García Guadilla, 2003, p. 19). Paralelamente, las universidades públicas de América Latina siguen siendo los principales focos de creación de conocimiento en la región. En muchos casos, ofrecen la mejor enseñanza de grado disponible. Desempeñan un papel importante en la difusión y aplicación del conocimiento, particularmente a través de la extensión, que las vincula con sectores socialmente postergados.

Esa preservación de ciertos logros y la incorporación de varias innovaciones importantes, en el marco de la impactante "masificación" y de las agudas carencias materiales, no se puede entender sin tener en cuenta algo que los comentaristas externos a menudo no ven: pese a los numerosos defectos de esas instituciones, a su interior se realizan, a menudo contra la corriente, un cúmulo de esfuerzos, desiguales y relativamente aislados, pero en conjunto gravitantes, que demuestran que en la universidad latinoamericana conserva vigencia la noción de servicio público.

Pero tales esfuerzos por lo general no se articulan en acciones transformadoras globales de largo aliento. Ello se retroalimenta con otra tendencia significativa, la que apunta al sensible debilitamiento de la cogestión democrática de las universidades públicas. Ya hemos subrayado el vigor por lo general escaso de las iniciativas reformistas "desde adentro". Refiriéndose a la Argentina se ha afirmado algo que seguramente vale en varias otras naciones latinoamericanas: "El país requiere un sistema de educación pública, ciencia y tecnología aggiornado e innovador, socialmente integrado, condición esencial de la competitividad y la justicia social auténticas. Y eso requiere sumar inversión e innovación con el objetivo de una transformación fuerte. Si la universidad misma no produce una autoevaluación de sus limitaciones para 
cumplir con ese objetivo y no diseña una estrategia de mediano y largo plazo para lograrlo, tendrá serios problemas para legitimar sus reclamos de recursos ante la misma sociedad" (Coraggio, 2003, p. 118).

Recapitulemos. Un documento de IESALC (2003), varias veces mencionado antes, que empieza afirmando que a fines de los '90 se inició una nueva fase, a la que califica de "Tercera Reforma", concluye sosteniendo que desde 1998 hasta el presente no se han producido en la ES latinoamericana cambios significativos ni reformas integrales y profundas. En las universidades hispanoamericanas, la única reforma con mayúscula fue la de Córdoba; no hubo otra ni la hay en curso. Una nueva reforma es imprescindible pero no llega a definirse (Arocena y Sutz, 2000), aunque dispone de sólidos sostenes parciales en multitud de esfuerzos de cambio, que debieran ser articulados, y también cuenta con cierto apoyo en las declaraciones referentes a la educación permanente de alto nivel. Pero ésta, en los hechos, ocupa un lugar marginal, lo cual constituye el principal obstáculo para el avance de la nueva reforma.

En la casi siempre desigual tensión entre cambios deliberadamente impulsados y cambios inducidos por "las circunstancias", estos últimos predominan ampliamente en la Es de América Latina. En ese contexto, no es mayormente significativa la contribución del sector a la superación del subdesarrollo de la región.

\section{Conocimiento y subdesarrollo}

El subdesarrollo no sólo presenta grados y facetas muy distintas según las diversas regiones; además combina, a lo largo del tiempo, continuidades notables y cambios también importantes. Entre estos últimos, los más relevantes se asocian a la emergencia, en los viejos países "centrales" y también en algunos nuevos, de lo que cabe denominar la "sociedad capitalista del conocimiento". La denominación alude tanto a lo técnico productivo como a lo social e institucional o, si se prefiere, al núcleo central de las fuerzas productivas y a las relaciones de producción predominantes (nuestro enfoque del tema ha sido elaborado en Arocena y Sutz, 2003, y resumido en Arocena, 2003). Se destaca tanto la relevancia creciente de la ciencia y la tecnología en la configuración de las formas del poder social, en los riesgos y en la distribución 
Las reformas de la educación superior y los problemas del desarrollo en...

de beneficios y perjuicios, como las interacciones entre ese proceso y la reestructura del capitalismo en los países centrales.

La tendencia a la privatización del conocimiento es una consecuencia directa de tales fenómenos. Un ejemplo entre muchos es el proyecto de incluir a la educación entre los "servicios" exportables sujetos a las reglamentaciones de la Organización Mundial del Comercio.

En tal contexto, se observa que las universidades en EUA se han estado reinventando a sí mismas como empresas, a partir de la aprobación de la Ley Bayh-Dole de 1980 que les permitió patentar hallazgos obtenidos con apoyo de dineros públicos. Profundas alteraciones en las pautas del trabajo académico están en curso, condicionadas por las estrechas relaciones con grandes empresas. En especial, se sostiene que las presiones de la industria farmacéutica han puesto en juego la integridad ética de la biomedicina (Horton, 2004). El proceso, en su conjunto, ha sido teorizado como una nueva "revolución académica" de la que surge la "universidad empresarial", caracterizada por la incorporación a las misiones clásicas de enseñanza e investigación de otra misión, la de contribuir al crecimiento económico a través de la capitalización del conocimiento avanzado (para una formulación reciente de la tesis, ver Etzkowitz, 2004).

La expansión de la ES privada se inscribe en la tendencia general a la privatización del conocimiento; se acelera sobre todo en algunas zonas donde coexisten una gran demanda social por ese tipo de enseñanza con una relativa desatención gubernamental. El sector privado de la ES en América Latina es uno de los que mayor incremento tuvo en el mundo; cabe estimar que ya da cuenta de más del $40 \%$ de la matrícula total.

Cuando el conocimiento se ubica en el centro de las relaciones de poder, una clave del subdesarrollo lo constituyen las divisorias del aprendizaje (Arocena y Sutz, 2003), vale decir, las diferencias entre personas y grupos sociales en materia de capacidades vinculadas al acceso a la educación y de oportunidades ocupacionales para usar creativamente esas capacidades de modo de seguir aprendiendo en el propio desempeño laboral.

La matrícula terciaria da una primera idea de esas divisorias: en promedio, es de alrededor de $18 \%$ del correspondiente tramo de edad en América Latina y $60 \%$ en los países centrales. Miremos más de cer- 
ca algunos números (UNESCO, 2004). En 2001-2002, se graduaron en EUA unas 2.240.000 personas, en Japón 1.048.000, en Brasil 422 mil, en México 340 mil, en Argentina 140 mil y en Corea del Sur 563 mil. En números gruesos, las dos mayores potencias económicas gradúan más del $0.8 \%$ de su población cada año, Argentina y México menos del $0.4 \%$ y Brasil menos del $0.3 \%$, mientras que Corea del Sur, uno de los pocos países de rápido desarrollo humano durante las últimas décadas, supera el 1\%. La "sociedad del conocimiento" debe medirse ante todo por el conocimiento que tiene la gente. Centremos la atención en quienes, en la visión tradicional, ya han "concluido" su etapa educacional, las personas de 25 años y más. Durante los '90, en los países latinoamericanos para los que hay datos, entre el 9 y el $12 \%$ de ese conjunto contaba con educación "post-secundaria", proporción que se aproximaba al 20\% en Canadá, Dinamarca, Noruega, Japón; en Corea del Sur pasó de 9\% en 1980 a 21\% en 1995. En EUA era el 51\% en 2000 .

Si se considera no sólo la cantidad sino la calidad de la educación, resultarían todavía mayores las diferencias en las capacidades entre países centrales y periféricos. Pero aún es más grande la diferencia en las oportunidades para aprovechar tales capacidades, como lo muestra el que los "recursos humanos" altamente calificados se desplazan desde donde son escasos hacia donde son abundantes. El 50\% de los emigrantes a EUA desde Sudamérica y el $75 \%$ de los de Africa Subsahariana tienen educación terciaria (World Bank, 2002, p. 18).

Las divisorias del aprendizaje son profundas y se están ampliando, constituyendo un factor mayor de la dependencia económica, política y aún ideológica de las "periferias" y "semiperiferias" a los "centros".

Esa dependencia se manifiesta en la ES por ejemplo a través de su internacionalización y del surgimiento de un "mercado educativo" a distancia, vinculado al auge contemporáneo de la enseñanza virtual, en el que predominan los países centrales de habla inglesa (García Guadilla, 2003). Ello plantea grandes dificultades para la incidencia nacional en la calidad y los valores de la ES, en las pautas que la orien$\tan y$, también, en sus fundamentales interacciones con la generación y el uso social del conocimiento.

Hemos subrayado que durante el último cuarto de siglo, en los intentos de cambiar la ES latinoamericana, han primado las visiones y 
Las reformas de la educación superior y los problemas del desarrollo en...

los impulsos "desde afuera". Los factores comentados en esta sección sugieren que el centro de gravedad de esa incidencia se seguirá desplazando del "afuera" nacional al "afuera" internacional. Sólo esfuerzos colectivos y deliberados de largo aliento podrían generar una inflexión en semejante tendencia.

\section{La educación superior en un nuevo desarrollo}

Es relativamente amplio el reconocimiento de que las estrategias económicas y políticas predominantes en América Latina desde las crisis de los ' 80 han arrojado pobres resultados. Se abre pues una oportunidad para un nuevo desarrollo, distinto tanto en lo que hace a las metas como a las estrategias. En términos normativos, pensamos en términos de desarrollo humano autosustentable, entendido como conjunto de transformaciones que apuntan a la mejora integral de la calidad de vida de la gente, preservando recursos y posibilidades de las generaciones futuras al mismo tiempo que se construye en el presente los sustentos sociales y materiales necesarios para afrontar los problemas del mañana.

En tal perspectiva, al menos tres grandes lineamientos para la acción constituyen pilares imprescindibles $\mathrm{y}$, a la vez, compatibles con una pluralidad de opciones políticas específicas.

1) Hace falta una estrategia económica alternativa, orientada a agregar valor de conocimiento y calificación a toda la producción de bienes y servicios. Predomina en América Latina la exportación de productos con bajo "valor agregado" de ese tipo, a cambio de otros con alto valor; ese intercambio desigual impulsa a abatir costos internos degradando las condiciones laborales y depredando el ambiente. Semejante opción es éticamente inaceptable, ecológicamente insustentable y económicamente ineficiente. La alternativa no consiste en centrar los esfuerzos sólo en las ramas de "alta tecnología" sino en utilizar los avances de la técnica para elevar el nivel de todas las ramas productivas, en particular las "tradicionales", donde existe una rica experiencia encarnada en mucha gente, que debe ser potenciada. Semejante estrategia requiere un gran avance en la generación endógena de conocimientos y, más aún, en la extensión de capacidades a la población en general. 
2) Hace falta superar la paralizante dicotomía entre mercado y Estado, apuntando a un desarrollo desde los actores. Ello requiere reorientar y accelerar la gestión pública - en particular involucrando activamente a los propios funcionarios para construir un Estado capaz de articular el accionar de los distintos agentes colectivos imprescindibles para un desarrollo integral. Para lograrlo es necesario ampliar tanto el conocimiento de la realidad social como las capacidades comunicacionales y de interacción entre grupos diferentes.

3) Hace falta generalizar la educación avanzada y permanente, entendida como la extensión a la mayoría de la población de las posibilidades de acceder a diversas formas de la enseñanza terciaria, que abran a su vez nuevas opciones, de modo de permitir que todos los que quieran puedan seguir aprendiendo siempre, en nivel avanzado y en permanente conexión con el desempeño laboral. Si no se avanza en esta dirección, las divisorias del aprendizaje consolidarán el subdesarrollo.

El corazón de la reforma universitaria latinoamericana y la clave de sus logros - desiguales y parciales pero reales - fueron el proyecto de transformar y democratizar las aisladas, atrasadas y elitescas universidades de comienzos del siglo XX, para convertirlas en herramientas para la democratización y el desarrollo de sociedades desiguales y dependientes. La reforma cosechó ciertos éxitos a partir de la convergencia de relevantes actores "internos" y "externos" a las instituciones de educación superior; ésta no se cambia para bien desde la autarquía ni desde la imposición desde afuera. Colaborar a la generalización de la educación avanzada permanente, y más en general, a la construcción de los pilares interconectados de un nuevo desarrollo debiera ser la idea fuerza de una nueva reforma. Ella será imposible sin la conjugación de esfuerzos "desde afuera" y "desde adentro".

Años atrás, "salir de las dictaduras" constituyó un proyecto ampliamente compartido, que galvanizó y articuló el accionar colectivo de sectores muy diversos, gestando a la vez avances democratizadores y una mayor valoración de la democracia. Luego, la persistencia de las penurias y de la miseria, junto con la consolidación de políticas rutinarias y aún corruptas, extendieron el desencanto con la democracia misma. Hoy se han abierto ciertas posibilidades para un nuevo desarrollo des- 
Las reformas de la educación superior y los problemas del desarrollo en...

de los actores, que podría constituirse en una noción orientadora que eleve los niveles de participación y así vigorice a la democracia.

Si llega a plasmarse esa retroalimentación entre desarrollo y ejercicio de la ciudadanía, las instituciones de ES tendrán que afinar enfoques "desde adentro hacia afuera". Mencionemos algunos de los varios temas que debieran figurar en la agenda.

- Cuando los valores y las prácticas democráticas vuelven a ser objeto de preocupación, es sorprendente la desatención que rodea, incluso dentro de las universidades públicas, a la temática de la revitalización del cogobierno, potencial escuela de ciudadanía para millones de personas.

- Ampliar la cobertura terciaria es una contribución necesaria al desarrollo, que se ve perjudicada por los aranceles, pero el acceso a la ES pública es también un privilegio individual que la sociedad paga, por lo que convendría promover contrapartidas de servicio civil universitario, de estudiantes y graduados, que robustecerían a la misión de extensión y darían más sustancia al componente social de la enseñanza pública.

- Generalizar más allá de los papeles la enseñanza avanzada permanente exige una inmensa diversificación pedagógica, pues hay que aprender a enseñar a personas muy diferentes, en sus edades, experiencias, conocimientos e inserciones sociales.

- Semejante expansión de la enseñanza es simplemente inviable si parte sustantiva de los tiempos, las capacidades y las infraestructuras disponibles en la producción no son utilizadas para la educación en colaboración con el sistema de enseñanza. Avanzar en esa dirección significa caminar hacia una sociedad de aprendizaje.

La idea latinoamericana de universidad forjada durante el ciclo de la reforma podría conocer un nuevo auge en el siglo XXI si, disociándola de cualquier pretensión exclusivista, se reivindica la democratización del conocimiento como misión definitoria de las instituciones públicas de ES.

\section{Conclusión: ¡cuál es la agenda de la universidad latinoamericana?}

La caridad bien entendida empieza por casa; las obligaciones también. Hemos sido mucho más fuertes en la crítica que en la propuesta de 
alternativas. Mañana, muchos se preguntarán qué lugar efectivo ocupaban, en la agenda de la universidad latinoamericana de comienzos del siglo XXI, las cuestiones entretejidas del desarrollo integral y de la generalización de la enseñanza avanzada permanente.

Recebido e aprovado em setembro de 2004.

\section{Referencias bibliográficas}

ALBORNOZ, O. Venezuelan higher education: the trend toward State control. International Higher Education, n. 31, 2003. p. 16-18.

ALTBACH, P.; DAVIS, T. Notas para un diálogo internacional sobre educación superior. In: AltbaCH, P.; McGill, P. (Ed.). Educación superior en el siglo XXI. Desafío global y respuesta nacional. Buenos Aires: Biblos, 2000. p. 21-29.

ALTBACH, P.; McGILL, P. (Ed.) Educación superior en el siglo XXI. Desafío global y respuesta nacional. Buenos Aires: Biblos, 2000.

AROCENA, R.; SUTZ, J. La nueva reforma universitaria vista desde el Uruguay. Avaliação - CIPEDES, n. 3 (10), 2000. p. 5-15.

AROCENA, R.; SUTZ, J. La universidad latinoamericana del futuro. Tendencias - Escenarios - Alternativas. Mexico: Editorial UDUAL, 2001a.

AROCENA, R.; SUTZ, J. Changing knowledge production and Latin American universities. Research Policy, n. 8 (30), 2001b. p. 1.221 1.234 .

AROCENA, R.; SUTZ, J. Subdesarrollo e innovación. Navegando contra el viento. Madrid: Cambridge University Press, 2003.

AROCENA, R.; SUTZ, J. Latin American universities: from an original revolution to an uncertain transition. Higher Education, 2004. (no prelo).

AROCENA, R. Qual o futuro de idéia latino-americana de universidade? In: Dourado, L.; Catani, A.; Oliveira, J. (Org.). Políticas e gestão 
Las reformas de la educación superior y los problemas del desarrollo en...

da educação superior. Transformações recentes e debates atuais. São Paulo: Xamã; Goiânia: Alternativa, 2003. p. 31-50.

BENTANCUR, N. Las politicas universitarias en la década del noventa. Análisis de cinco casos nacionales. Facultad de Ciencias Sociales, Universidad de la República, Montevideo, 2002.

BERNASCONI, A. Private higher education in Chile: the new exceptionalisms. International Higher Education, n. 32, 2003. p. 18-19.

CAMPBELL, J.C. La educación superior en Chile: efectos de la modernización. In: Sisson de Castro, M.L.; Obino Correa Werle, F. (Org.). Educação comparada na perspectiva de globalização e autonomia. São Leopoldo: Editora da UNISINOS, 2000. p. 11-126.

CATANI, A. (Org.). Novas perspectivas nas politicas de educação superior na América Latina no limiar do século XXI. Campinas: Autores Associados, 1998.

CATANI, A.M.; OLIVEIRA, J.F. Educação superior no Brasil. Reestruturação e metamorfose das universidades públicas. Petrópolis: Vozes, 2002.

CATANI, A.M.; PORTELA DE OLIVEIRA, R. (Org.). Reformas educacionais em Portugal e no Brasil. Belo Horizonte: Autêntica, 2000.

CORAGGIO, J.L. La crisis y las universidades públicas en Argentina. In: Molis, M. (Comp.). Las universidades en América Latina: ¿reformadas o alteradas? La cosmética del poder financiero. Buenos Aires: CLACSO, 2003. p. 109-122.

CEPAL. Balance preliminar de las economías de América Latina y el Caribe 2003. Santiago de Chile: CEPAL, 2003.

DIAS SOBRINHO, J. Quase-mercado, quase-educação, quase-qualidade: tendências e tensões na educação superior. Avaliação, v. 7, n. 1, 2002. p. 9-33.

DOURADO, L.; OLIVEIRA, J.; CATANI, A. Transformações recentes e debates atuais no campo da educação superior no Brasil. In: DourAdo, L., Catani, A. e Oliveira, J. (Org.). Políticas e gestão da educação superior. Transformações recentes e debates atuais. São Paulo: Xamã; Goiânia: Alternativa, 2003. p. 17-30. 
DOURADO, L.; CATANI, A.; OlIVEIRA, J. (Org.). Politicas e gestão da educação superior. Transformações recentes e debates atuais. São Paulo: Xamã; Goiânia: Alternativa, 2003.

ETZKOWITZ, H. The evolution of the entrepreneurial university. International Journal of Technology and Globalization, v. 1, n. 1, 2004. p. 64-77.

GARCÍA GUADILLA, C. La reforma de la educación superior en Venezuela desde una perspectiva comparada. In: Catani, A. (Org.). Novas perspectivas nas politicas de educação superior na América Latina no limiar do século XXI. Campinas: Autores Associados, 1998. p. 189-201.

GARCÍA GUADILLA, C. Balance de la década de los '90 y reflexiones sobre las nuevas fuerzas de cambio en la educación superior. In: Molis, M. (Comp.). Las universidades en América Latina: ¿reformadas o alteradas? La cosmética del poder financiero. Buenos Aires: ClaCsO, 2003. p. 17-37.

GONZÁLEZ, L.E. Acreditación y fomento de la calidad. La experiencia chilena de las últimas décadas. In: Molis, M. (Comp.). Las universidades en América Latina: ¿reformadas o alteradas? La cosmética del poder financiero. Buenos Aires: ClACSO, 2003. p. 141-159.

HORTON, R. The dawn of McScience. The New York Review of Books, v. LI, n. 4, 2004. p. 7-9.

IESALC. Reformas e innovaciones en la educación superior en algunos paises de América Latina y el Caribe, entre los años 1998 y 2003. Instituto Internacional de la UNESCO para la Educación Superior en América Latina y el Caribe, 2003.

KROTSCH, P. Gobierno de la educación superior en Argentina: la política pública en la coyuntura. In: CATANI, A. (Org.). Novas perspectivas nas políticas de educação superior na América Latina no limiar do século XXI. Campinas: Autores Associados, 1998. p. 203-228.

MOLIS, M. Un breve diagnóstico de las universidades argentinas: identidades alteradas. In: Molis, M. (Comp.). Las universidades en América Latina: ¿reformadas o alteradas? La cosmética del poder financiero. Buenos Aires: CLACSO, 2003. p. 203-215. 
Las reformas de la educación superior y los problemas del desarrollo en...

MOLIS, M. (Comp.). Las universidades en América Latina: ¿reformadas o alteradas? La cosmética del poder financiero. Buenos Aires: CLACSO, 2003.

OROZCO SILVA, L.E. La reforma de la educación superior en Colombia: balance crítico. In: CATANI, A. (Org.). Novas perspectivas nas políticas de educação superior na América Latina no limiar do século XXI. Campinas: Autores Associados, 1998. p. 269-291.

PARRA SANDOVAL, M.C. Los cambios en la política de educación superior venezolana y la profesión académica. Avaliação, v. 7, n. 1, 2002. p. 79-96.

SGUISSARDI, V. O desafio de educação superior no Brasil: quais são as perspectivas? Avaliação, v. 5, n. 2, 2000. p. 7-24.

SISSON DE CASTRO, M.L; OBINO CORREA WERLE, F. (Org.). Educação comparada na perspectiva de globalização e autonomia. São Leopoldo: Editora da UNISINOS, 2000.

TOYE, J. Dilemmas of development. Oxford: Basil Blackwell, 1987.

UNESCO Global education digest. Montreal: Institute for Statistics. Disponible en: <http://www.uis.unesco.org>. Acceso en: 2004.

VIOR, S. Argentina: políticas para la educación superior en la década del '90. In: Sisson de Castro, M.L.; Obino Correa Werle, F. (Org.). Educação comparada na perspectiva de globalização e autonomia. São Leopoldo: Editora da UNISINOS, 2000. p. 127-135.

WORLD BANK. Constructing knowledge societies: new challenges for tertiary education. Washington, D.C.: World Bank, 2002. 